\title{
Counting the Chinese Population
}

To know how large the population of China is, and especially how quickly it is growing, is important because the population of China is so large. The Population Division of the United Nations estimated earlier this year that there are 760 million people in mainland China, just about 20 per cent of the estimated population of the world as a whole. But the estimates of the Chinese population are more seriously in error than those of any other major country. The United Nations modestly says that the true population in mid-1969 may have been anything between 732 million and 828 million.

The difficulty, of course, is the lack of accurate census data-the most recent census, itself an unconventional process by Western standards, was carried out as long ago as 1953. Given these uncertainties, it is no wonder that the Population Council of the United States has in the past few weeks excited great interest by its publication of a report on health and family planning services in mainland China by Dr Anibal Faundes and Dr Tapani Luukkainen of Santiago and Helsinki respectively (Studies in Family Planning, 3, $165 ; 1972$ ). The two obstetricians spent two weeks in China in March this year and have now told a traveller's tale which has been widely interpreted as a sign that contraceptive devices of various kinds are now widely used in China and that, as a result, the immediate outlook for the growth of the Chinese population is more cheerful than has usually been supposed. Unfortunately, however, the necessarily anecdotal character of this report will prevent demographers from throwing their hats too high in the air.

Plainly, the government in Peking is as much at a loss as demographers elswhere, for the decentralization of public administration means that only provincial and commune governments are in a position to monitor both the effectiveness of public health and the growth of the population within their parishes. There is apparently some hope that a more accurate picture of the demographic characteristics of the Chinese population will emerge from the registration of voters for the 1973 elections, but that is not a substitute for an accurate census. What Drs Faundes and Luukkainen have in the circumstances done is to provide estimates of birth and death rates in the cities of Peking and Shanghai which are themselves derived from information collected by the city governments. In Peking, for example, the annual birth rate is said to be 18.8 per thousand, and mortality 6.4 per thousand of total population, which corresponds to a rate of increase of 1.24 per cent per year. In Shanghai, a more western city, the birth rate is 12.08 per thousand and the mortality 5.2 per thousand, corresponding to a rate of increase of 0.69 per cent per year. These rates of increase are much lower than the estimate of between 1.9 and 2.0 per cent per year for mainland China as a whole. The difficulty is, of course, that the natural increase of an urban population in a developing country may frequently be much less than that of the surrounding rural population. Given the correlation between low infant mortality (easier to achieve in cities), the availability of education and personal prosperity and comparatively low birth rates, it is no surprise that city statistics are misleading.

In the same spirit, what Drs Faundes and Luukkainen have to say about the practice of contraception in and near Peking and Shanghai must also be taken with a grain of salt. The most striking part of their report is their declaration that 65 per cent of married couples in cities practise contraception and that in Shanghai no less than 89 per cent of married couples use some contraceptive method. It is extremely hard to believe this estimate-in the United States, for example, a survey completed in 1965 showed that 84 per cent of white couples had at some time practised contraception. In China, tubal ligations appear to be much more common than in the west. Abortions are easy to come by. Intrauterine devices are said to be more widely used in rural districts than in cities, where contraceptive pills appear to be more popular.

What does this imply? The only sure inference from the report by Drs Faundes and Luukkainen is that, in the cities at least, both the population and the public health authorities have heeded diligently the pleadings of the central government that the containment of population growth should be an important part of public policy. That is a hopeful sign, but much will depend on how quickly the rural areas will follow suit.

But nobody can be sure, which is why there is an urgent need that the government of China should organize a much better method of monitoring population growth than is available at present.

\section{Years Ago}

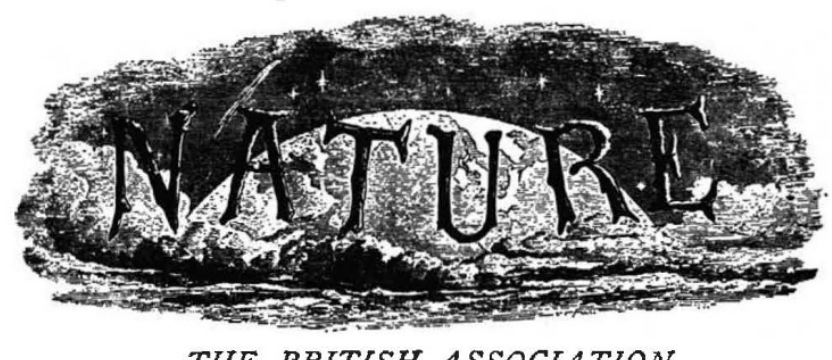

THE BRITISH ASSOCIATION

\begin{abstract}
THE recurrence of our annual Congress of Science naturally leads us to reflect on the position which the British Association occupies in our social economy, and on the part it is qualified and, perhaps, destined to play. Whilst other scientific societies occupy themselves in giving publicity to results and speculations, and in rewarding with their medals successful labours, the British Association alone systematically undertakes to distribute the greater part of its income, about 2,000\%. per annum, in grants to enable men of science to conduct scientific investigations, and to institute inquiries with a view to possible future action. Stated briefly, this constitutes the broad distinction between the British Association and other scientific societies. As a publishing society it cannot vie with some other bodies, as, for instance, with the Royal Society. The great bulk of the papers it receives are published in abstract and but few in extenso; and it allows a greater latitude than other societies with regard to the reception of subjects which have been elsew here made public, thus constituting its proceedings, to a great extent, a résumé of the year's work - a characteristic quite in keeping with its practice of meeting but once a year.
\end{abstract}

From Nature, 6, 297, August 15, 1872. 